\title{
O patrimônio cultural de Governador Valadares (MG): algumas reflexões
}

Cristiana Maria de Oliveira Guimarães*

\section{Resumo}

Contemporaneamente, as cidades, como todo o resto, passam por significativas transformações. Transformações intrínsecas à sua própria definição e sentido, e outras relacionadas às expectativas e reivindicações em torno delas.

A idéia defendida é que as transformações acontecem em duplo sentido: de um lado, o sentido de uma expansão, em extensão; e de outro, um retorno, ao sentido de polis. Esse duplo movimento de extensão e retorno é relacionado a novos valores que se impõem hoje, ao pensarmos o urbano, entre os quais o direito à cidade. Entendemos que o direito à cidade inclui o direito ao patrimônio cultural, à preservação do meio ambiente, à possibilidade das diferenças, entre outros.

Nesse sentido, compreendemos que a preservação do patrimônio cultural conforma-se como uma nova questão urbana, que soma-se às "velhas questões urbanas" e, tal como essas, demanda discussões, análises e algumas alternativas.

A partir dessas ponderações, pretendemos estabelecer algumas reflexões sobre a questão do direito à cidade, representada pela preservação do patrimônio cultural, e o recente tratamento dispensado a essa questão, em Governador Valadares (MG).

Palavras-chave: Patrimônio. Direito à cidade. Questão urbana.

\section{The Governador Valadares urban heritage: some aspects}

\begin{abstract}
In our days, the cities, as all the rest go through significant transformations. Intrinsic transformations to its proper definition and direction, and others related to the expectations and claims around them.

The defended idea is that the transformations happen in two-ways: from one side, a sense (way) of an expansion, in extension; from the other side, a return, to the sense (way) of polis. This double movement of extension and return is related to new values of
\end{abstract}


the urban, mainly, the right to the city. We think the right to the city includes the right to the urban heritage, the sustainable development and social justice.

In this sense, we think the careful of the urban heritage is a new urban question, which adds some of the cities old problems. Then, it needs researches, analysis and some alternatives.

This paper intends to suggest some aspects about the right to the city, from the discussion of the urban heritage question in Governador Valadares city.

Key-words: Urban heritage. Right to the city. Urban question.

\section{O Patrimônio Cultural de Governador Valadares (MG): algumas reflexões}

Entre as questões que se colocam com grande proeminência em nossos dias está a cultura. Pano de fundo de outras mais amplas (ou específicas?), como o direito à diferença, tanto em relação ao gênero, raça ou opção sexual, o lazer e o desenvolvimento sustentável. A cultura, explorada sustentavelmente, possibilita o florescimento de diversas atividades ligadas, principalmente, ao turismo. A associação entre cultura e cidadania ultrapassa o meio acadêmico, angariando adeptos em vários segmentos sociais. Está particularmente sustentada pelas empresas, a partir da famosa "responsabilidade social" ou, poderíamos dizer, marketing social. Os investimentos empresariais em ações e programas que buscam a melhoria da qualidade de vida de determinada população, a partir da base cultural são, atualmente, bem recebidos pela sociedade, demonstrando serem esses valores assumidos por todos. Tornam-se mais freqüentes ações e projetos estatais, promotores da relação entre cultura e cidadania, apesar de, segundo alguns autores (FARIA; MOREIRA, 2005), esses ainda serem insuficientes e/ou inadequados. Ainda se faz presente, em muitos projetos e ações, principalmente naquelas originárias do Estado, em seus diversos níveis, a idéia única de cultura como manifestação artística; nesses casos, as ações ficam restritas a apresentações de espetáculos, exposições artísticas, etc. 
De outro lado, algumas ações têm sido desenvolvidas no âmbito do patrimônio cultural. Em Minas Gerais, tornou-se "revolucionária" a criação e implementação da Lei Estadual 12.040 de 28/12/1995, conhecida como Lei Robin Hood. Essa lei inclui ações referentes à educação, saúde, agricultura, preservação do meio ambiente e do patrimônio cultural, nos critérios de cálculo do repasse da parcela do ICMS devida aos municípios. Essas ações são avaliadas dentro de critérios previamente definidos e fiscalizados pelos órgãos competentes. No caso do patrimônio cultural, o Instituto Estadual do Patrimônio Histórico e Artístico de Minas Gerais - IEPHA/MG cumpre esse papel. Entre as exigências colocadas pelo IEPHA estão a existência de uma política municipal de preservação do patrimônio cultural e a criação e atuação efetiva de um conselho municipal de patrimônio cultural.

Essas exigências evidenciam outras mudanças em relação à preservação do patrimônio cultural: o órgão em nível estadual passa a gestor (gerenciador) das propostas e ações, deixando de ser o - único - executor. O município passa a ser o primeiro responsável pela política de patrimônio. O IEPHA/MG define essa opção no Programa Municipalização do Patrimônio Cultural de Minas Gerais. O âmbito local é valorizado, como o são os novos agentes - os parceiros públicos e privados, somados a diferentes setores institucionais. Esses passam a tomar parte na elaboração, discussões e decisões sobre a política patrimonial.

Nesse sentido, há a prerrogativa da criação e implementação de conselhos municipais para tratar da questão do patrimônio cultural. Os conselhos são órgãos híbridos, conformadores de uma nova forma institucional que envolve a partilha de espaços de deliberação entre as representações estatais e as entidades da sociedade civil (PEREIRA, 2000). Assim, conformam-se como um espaço institucional distinto, tanto do Estado quanto dos movimentos sociais; numa instância intermediária de debate e deliberação que não significa a supressão das instâncias formais e da atuação livre, autônoma e democrática da sociedade civil. Cumpre lembrar que os conselhos constituem-se como um dos instrumentos de gestão democrática, previstos na Constituição Federal de 1988. 
A partir das possibilidades (e exigências) abertas pela lei federal, associada no Estado de Minas Gerais, à existência da Lei Robin Hood, vários municípios iniciaram a implementação de uma política municipal de preservação do patrimônio cultural. Governador Valadares (1) não é exceção à regra. Em 2001 foi instituído, a partir de um decreto municipal, Decreto Municipal $n^{\circ} 6927$ de 19/03/2001 e referendado pela Lei Municipal 4646/99, o Conselho Deliberativo do Patrimônio Cultural - CDPC. Segundo seu Regimento Interno (PREFEITURA MUNICIPAL DE GOVERNADOR VALADARES, 2002), se caracteriza como: “órgão de normatização, consulta e deliberação do Poder Executivo no que diz respeito à preservação dos bens de valor cultural localizados no município de Governador Valadares."

Mesmo considerando o caráter preliminar da pesquisa em relação ao CDPC, fruto, apenas, das entrevistas realizadas com alguns conselheiros e de pesquisas iniciais, podemos apontar que o interesse pela sistematização da preservação do patrimônio cultural em Governador Valadares foi uma iniciativa governamental, e não o resultado de um processo de reivindicações populares. Iniciativa essa, originada, em grande parte, da existência da Lei Robin Hood.

Acredito que é possível relacionar a trajetória do CDPC a uma análise realizada a partir das relações local-global. Normas, valores, concepções de mundo e, inclusive, repasse de verbas oriundos do Mundo (SANTOS, 1994) alcançaram a dinâmica local. Dizendo de outro modo, entre as externalidades que interferiram na realidade valadarense está a proeminência da cultura, materializada na sua valorização, inclusive econômica, cujo exemplo paradigmático é a Lei Robin Hood. Contudo, elas não foram acompanhadas de uma verdadeira modificação na lógica local. $O$ valor preservação do patrimônio cultural não foi assumido como parte do urbano, possibilitador da melhoria da qualidade de vida e, mais que isso, de potencializador da conquista da cidadania através do exercício do direito à cidade. Todos esses quesitos são subsídios das novas normas relacionadas à preservação do patrimônio, desde a Constituição Federal de 1988 e o Estatuto da Cidade, em nível federal, às orientações do IEPHA/MG, em nível estadual. 
Localmente, ele continua restrito ao entendimento próprio às décadas de 1920 e 1930, no qual o patrimônio é constituído por bens isolados e particulares, possuidores de valores excepcionais.

A primeira gestão do CDPC foi atuante, identificando obras de relevância e realizando nove tombamentos municipais, listados a seguir: O Antigo Templo Presbiteriano, o Complexo da Santa, a Companhia Açucareira do Rio Doce, a Fachada da Antiga Cadeia Pública, as Fachadas da Antiga Sede dos Correios e Telégrafos e a Venda do Seu Margarido foram protegidos como bens imóveis; o Pico do Ibituruna foi tombado como Conjunto Paisagístico; e como bens móveis, o foram a Argola de Amarrar Solípedes, o Cadeiral do Júri, a Maria Fumaça e o Painel Cubista do Edifício Helena Soares.

Os tombamentos, em sua maioria, tiveram como objetos, bens de uso público, alguns, de propriedade pública, outros de ordem privada, mas não familiar, como o caso dos objetos pertencentes às Igrejas. Não houve conflitos, nem outras mobilizações significativas, em torno desses. A exceção se faz em dois planos: o único bem familiar, um imóvel, tombado é, até os dias de hoje, motivo de diversos protestos e de um processo judicial. Algumas iniciativas no sentido de cancelar o tombamento foram tentadas, pela família e pelo poder municipal, já em outra gestão, por pressão dessa, e de certo modo, da sociedade como um todo. Através do Decreto Municipal $n^{\circ} 8.413$ de 26/12/2005, a administração municipal revogou o tombamento do bem imóvel urbano, conhecido como Venda do Seu Margarido (VENDA, 2006; TRANSPARÊNCIA GV, 2006). O cancelamento do tombamento foi interditado judicialmente, através de uma liminar favorável à ação judicial de iniciativa popular, movida por alguns vereadores, solicitando a anulação do referido Decreto. A não aceitação deste tombamento está motivando um dos recursos mais antigos, graves e irremediáveis que acompanham a história da preservação do patrimônio cultural no Brasil: o proprietário, inconformado, deixa seu imóvel, literalmente tombar, fisicamente falando (Figura 1). 


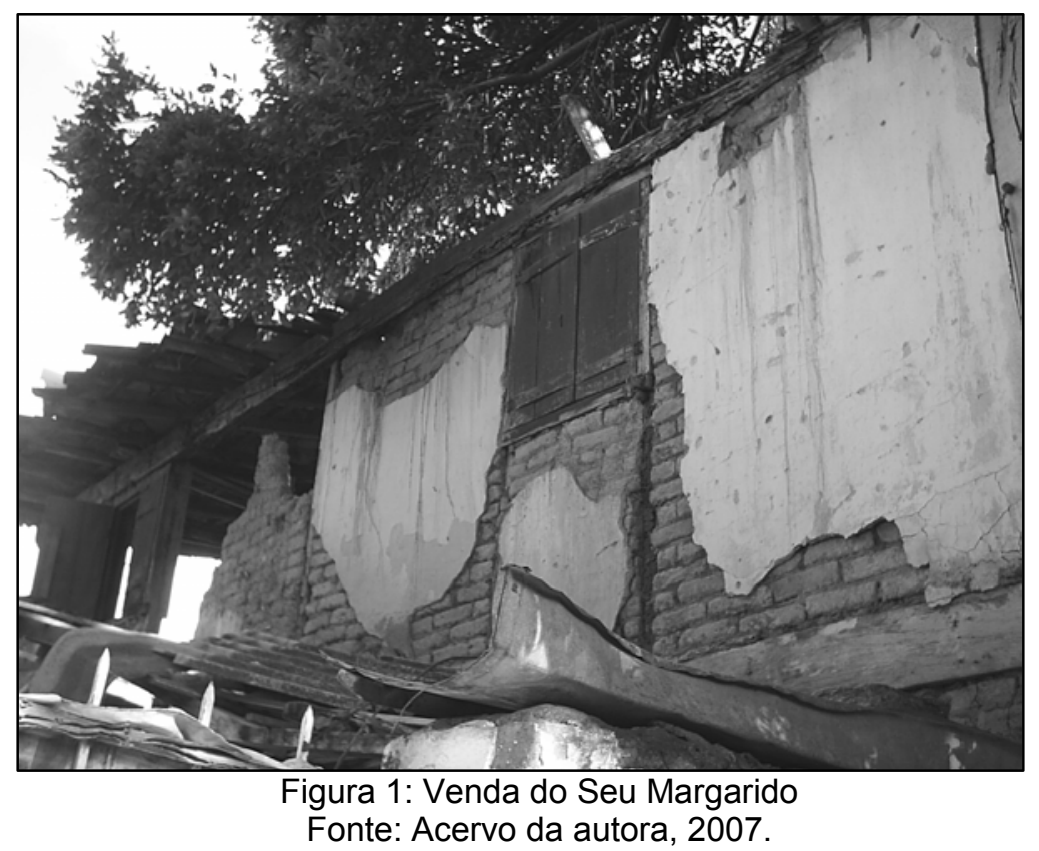

Algumas ações, como abraços simbólicos, projetos e reuniões foram realizados em relação à Venda do Seu Margarido, sem, contudo, conseguir efetiva sensibilização. Ao contrário, no imaginário local, a preservação do patrimônio tornou-se um perigo...

Governador Valadares, apesar das suas origens remontarem ao século 19, no imaginário de grande parte da população, é considerada uma cidade novíssima, "nascida" em 1938, a partir do Decreto de Benedito Valadares (2), então Governador do Estado de Minas Gerais. Assim, para grande parte de seus moradores, não há a questão do patrimônio cultural, pois não há, ainda consolidada, a questão da perda. $\mathrm{O}$ passado ainda não está distante e as mudanças não são sentidas como perda, mas como instauração do progresso. A exceção que confirma a regra é a Açucareira (3) (Figura 2), consagrada como referência na cidade, muito mais pelo seu caráter arquitetônico excepcional, do que como representante do passado. 


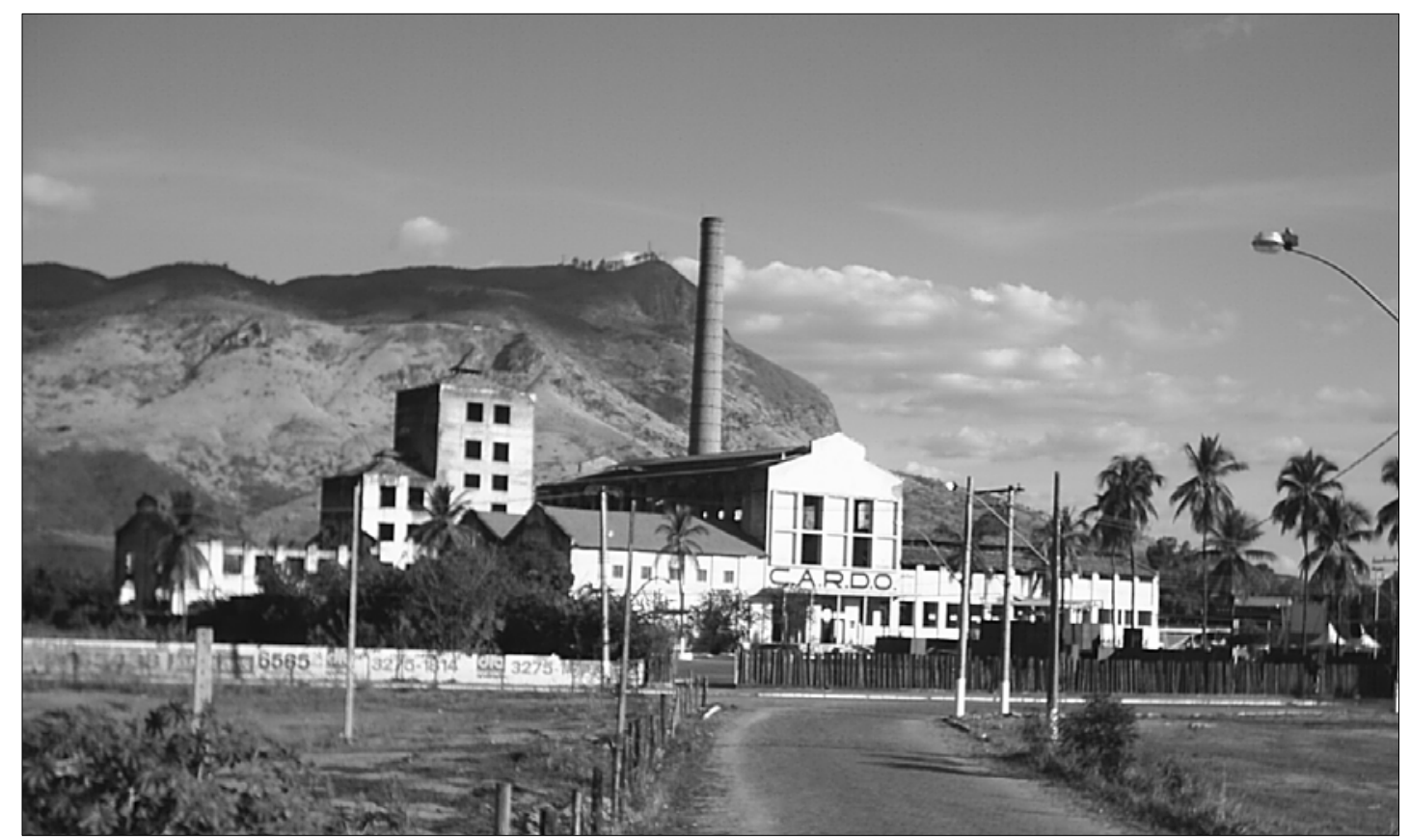

Figura 2: Açucareira com o Pico da Ibituruna ao fundo.

Fonte: Acervo da autora, 2007.

Logo após a primeira gestão do CDPC, a cidade teve significativos repasses de verbas. Contudo, esses não foram destinados ao re-investimento ao patrimônio. Somam-se a isso outras dificuldades, gerando uma significativa diminuição no repasse de verbas, entre os anos de 2002 e 2006, como mostra a Tabela 1. Apesar do CDPC continuar suas atividades, essas oscilam entre períodos de maiores e menores intervenções e ações.

Tabela 1: Repasse em reais para GV dos valores referentes ao ICMS - quesito Patrimônio Cultural. Fonte: Fundação João Pinheiro, 2007.

\begin{tabular}{|c|c|c|c|c|c|c|c|c|c|c|c|c|c|}
\hline ANO & JAN. & FEV. & MARÇO & ABRIL & MAIO & JUNHO & JULHO & AGOSTO & SET. & OUT. & NOV. & DEZ. & TOTAL \\
\hline 2002 & 6165,44 & 5790,35 & 5576,89 & 6097,75 & 5838,24 & 6044,57 & 6497,57 & 6546,27 & 7004,94 & 6819,60 & 7011,79 & 7233,56 & 76626,41 \\
\hline 2003 & 3065,51 & 3589,66 & 3480,37 & 3568,70 & 4284,71 & 4575,19 & 4671,01 & 4487,07 & 4719,07 & 4572,97 & 4910,49 & 5251,27 & 51176,02 \\
\hline 2004 & 6901,30 & 6718,39 & 6704,58 & 7132,23 & 7109,34 & 7263,69 & 7234,68 & 8244,27 & 7853,93 & 8136,75 & 8917,58 & 8575,68 & 90792,42 \\
\hline 2005 & 4375,24 & 3323,63 & 3358,19 & 3596,51 & 3793,98 & 3483,49 & 4297,97 & 4108,17 & 3488,41 & 3539,41 & 3573,87 & 4499,40 & 45438,27 \\
\hline 2006 & 1199,35 & 820,47 & 836,61 & 886,57 & 900,96 & 846,18 & 933,24 & 1028,91 & 898,88 & 1102,89 & 964,56 & 1065,48 & 11484,10 \\
\hline
\end{tabular}

É possível relacionar os maiores repasses aos processos de tombamentos, já que a maioria, entre os listados pelo IEPHA/MG (2007), foi efetivada em 2004. Seus processos incluem a elaboração de dossiês, que investigam e relatam a história do bem, o estado de conservação e outras informações importantes. Mesmo considerando 
a importância desse instrumento de proteção, é consenso, hoje, sua insuficiência para abarcar todas as questões do patrimônio, principalmente aquelas ligadas à dinâmica urbana. As orientações do IEPHA/MG (2007) apontam:

\begin{abstract}
São diversos os mecanismos à disposição dos municípios, tanto de controle urbanístico como de ordem fiscal e penal. O Plano Diretor [...] deve estabelecer as diretrizes gerais da política local de proteção. Do ponto de vista do controle urbanístico, são bastante eficazes as medidas que regulam o uso e a ocupação do solo, consubstanciadas na respectiva legislação urbanística. Do ponto de vista das medidas de ordem penal e fiscal, estabelecem-se critérios de incentivo à preservação ou compensações a danos ao patrimônio. [...]. Algumas cidades, já a [preservação do patrimônio] incorporam no seu zoneamento básico, definindo setores especiais de preservação, com regras urbanísticas próprias, com potencial construtivo compatível ou restrito, de modo a não estimular sua destruição ou substituição. No caso de leis já existentes, é possível o estabelecimento de um sobre-zoneamento que confira regras adicionais aos trechos urbanos em que essas já tenham sido estabelecidas [...] podendo chegar à proposição de diretrizes para intervenção no desenho urbano.
\end{abstract}

Essas considerações nos levam a outra observação sobre a política da proteção do patrimônio posta em prática em Governador Valadares: essa aparece desvinculada de outras questões urbanas. Alguns casos são paradigmáticos e nos servirão de exemplos.

Há uma área, no Bairro Esplanada, cuja ocupação data da década de 1950, onde ainda predominam as relações de vizinhança, a relação rua/morador e uma ambiência caracterizada pela pouca densidade, devido à significativa presença de jardins e quintais. Esse último fator é de grande relevância, considerando a necessidade de diminuição de áreas impermeabilizadas, e ainda, de controle e suavização das altas temperaturas características do local. A Lei de Uso e Ocupação do Solo permite um gabarito de até 18 pavimentos, na área acima mencionada. Vale dizer, que se essa era, justamente, a porção mais valorizada pelo mercado imobiliário, essa condição está reforçada. Nesse sentido, há o risco iminente da substituição das residências unifamiliares pelas torres de apartamentos, como, de fato, vem acontecendo recentemente (4).

Essa problemática não alcançou a política de patrimônio, mostrando a não amarração de suas ações e propostas ao planejamento urbano como um todo. Há, ainda, uma certa indiferença sobre as possibilidades de somar-se à legislação urbanística, ou pela 
reafirmação das suas colocações, ou pela limitação dessas. Isso seria importante por constituir um outro nível de jurisdição, talvez mais independente de possíveis lobbies e pressões do mercado imobiliário e da construção civil. Além disso, estaria colocada a necessidade de aprovação por uma instância deliberativa e participativa, como o é o CDPC. Os conselhos não são virtuosos em si, mas são um campo de disputas e negociação, e seu grau de autonomia poderá ser ou não ampliado, a depender do grau de unidades de forças da sociedade civil nele presentes e da natureza das forças políticas dominantes. Em outras palavras, apesar de não serem garantia da melhor decisão, os conselhos constituem uma nova institucionalidade que não se reduz a formalidades. Incorporam novos agentes ao processo político e ampliam a representação na arena de definição de políticas com a participação de usuários e prestadores de serviços. Através da identificação das necessidades, modificam a natureza dos filtros pelos quais o sistema tradicional processa as demandas da população, sistema que está voltado principalmente para interesses particularistas ou corporativos. Constroem, assim, uma forma de processamento das demandas balizada no interesse público e constituída, não apenas pelas representações sociais que fazem parte dos conselhos, mas pelo processo de discussão pública, explicitação de interesses e de negociação (TEIXEIRA, 2000).

A transformação de um fenômeno qualquer em um problema a ser enfrentado social e politicamente é um constructo, uma construção social. Recorrendo a Habermas (1999), podemos entender que os espaços públicos, domínios de interação social comunicativa, podem influir nos âmbitos sistêmicos, inclusive nos domínios das instituições do Estado. Ao mesmo tempo, explica-se e descortina-se a possibilidade de um constructo social ser levado ao âmbito político e transformado em questão política. A partir disso, torna-se possível a conquista de suficiente pressão pública para o seu processamento e resolução, inclusive institucionalmente. Esse, no nosso entender, poderia ter sido o processo de inserção da preocupação com o patrimônio cultural na legislação urbana. Contudo, em Governador Valadares, as questões urbanas ainda não são entendidas como referentes ao patrimônio cultural; pertinentes a esse estão 
questões singulares, relativas a obras excepcionais, como indicam os outros exemplos a seguir.

A cidade é margeada pelo Rio Doce (Figura 3), sendo a sua ocupação e desenvolvimento devedores dessa condição. A preocupação com a paisagem urbana, resultante dessa característica, não é evidenciada na política de proteção do patrimônio.

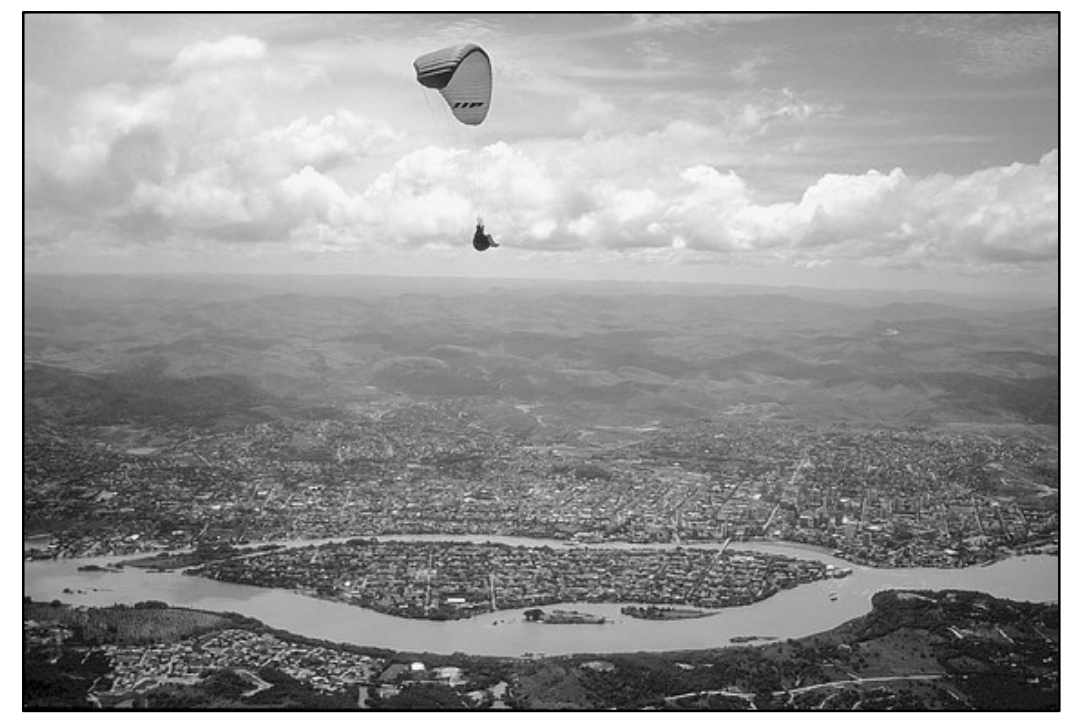

Figura 3: Vista de Governador Valadares desde a Ibituruna. Fonte: Jérome Sarthe, 2002.

Disponível em www.hippolyte.free.fr/brazil/thumbnail.html

$\mathrm{Na}$ outra margem no Rio Doce, em frente à cidade, há um acidente geográfico importante, símbolo identitário para os valadarenses e marco da paisagem local (Figura 4). Os moradores o chamam "Pedra da Ibituruna", ou simplesmente "a Ibituruna". A pedra é avistada desde longe e, além disso, garante à cidade a condição de sede de campeonatos nacionais e internacionais de diversas modalidades de vôo livre e, conseqüência disso, o título de Capital Mundial do Vôo Livre. 


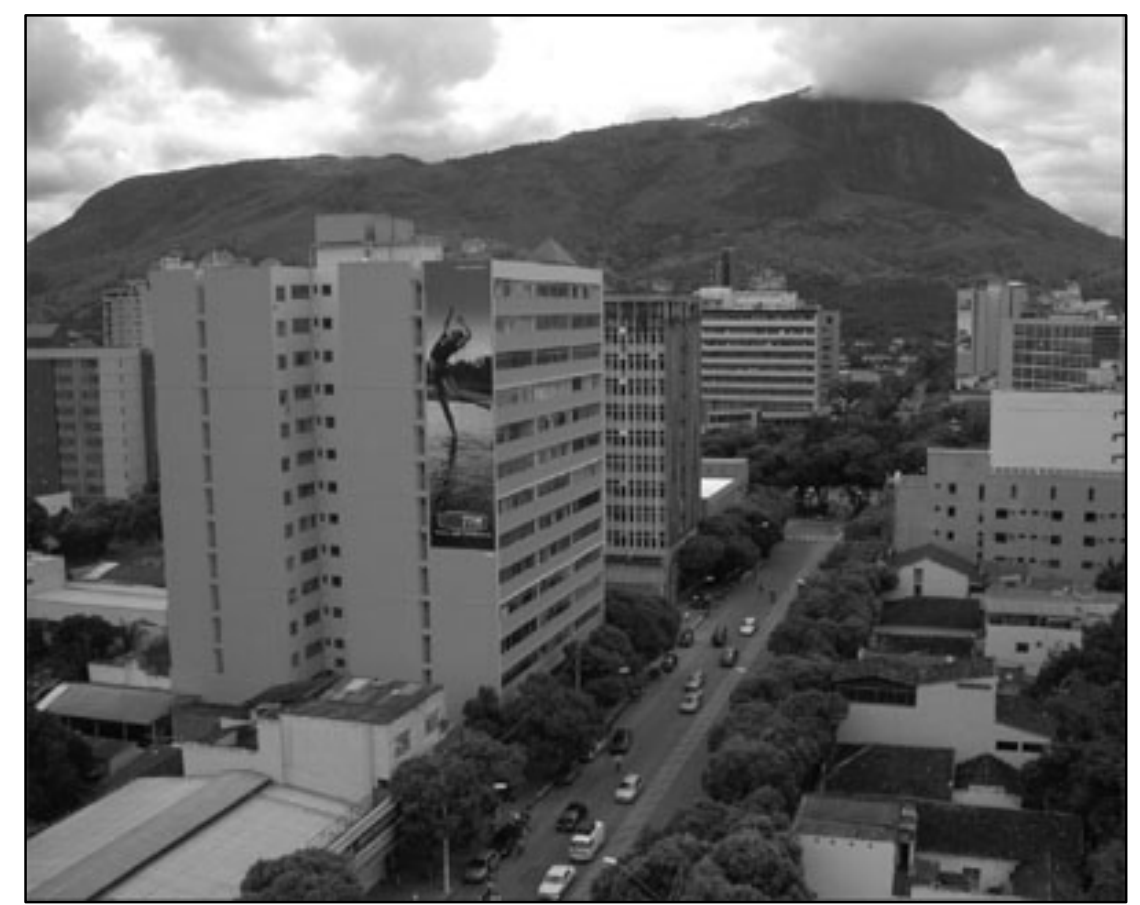

Figura 4: Vista da área central com o Pico da Ibituruna ao fundo. Fonte: Acervo Luiza Terezinha Coelho.

Em relação à Ibituruna, a política de patrimônio tem atuações diversas. O CDPC reafirma o tombamento estadual, realizado pela Constituição Estadual de 1989, como conjunto paisagístico. Porém, não são perceptíveis medidas para preservação das condições da paisagem em relação ao conjunto cidade/rio/lbituruna. A permissão da construção de edificações com gabaritos altos, em locais que impossibilitam a visibilidade do rio, favorece a futura conformação de uma barreira, à semelhança das orlas marítimas brasileiras. Impedem, ainda, a vista da Ibituruna, ou a diminuição do impacto da sua altitude em relação ao terraço fluvial, sobre o qual se consolidou a cidade. Há uma perda significativa causada pela não articulação do ambiente construído com as especificidades da paisagem natural. Isso seria, do nosso ponto de vista, um dos principais traços a serem preservados como identidade e patrimônio cultural.

Em outro âmbito, a área da Ibituruna é "referenciada" pela política de preservação do meio-ambiente. Em nível estadual é considerada uma APEE - Área de Proteção Especial Estadual; em nível municipal foi classificada como APA - Área de Proteção 
Ambiental, pela Política de Meio Ambiente Municipal, através da Lei Complementar n55 de 27 de maio de 2004 (CÂMARA MUNICIPAL DE GOVERNADOR VALADARES, 2004).

Voltando à questão da ambiência urbana e o patrimônio cultural, um exemplo recente ilustra a separação entre eles: a construção de uma torre de apartamentos ao lado do outeiro da Catedral, em lotes limítrofes a essa (Figura 5).

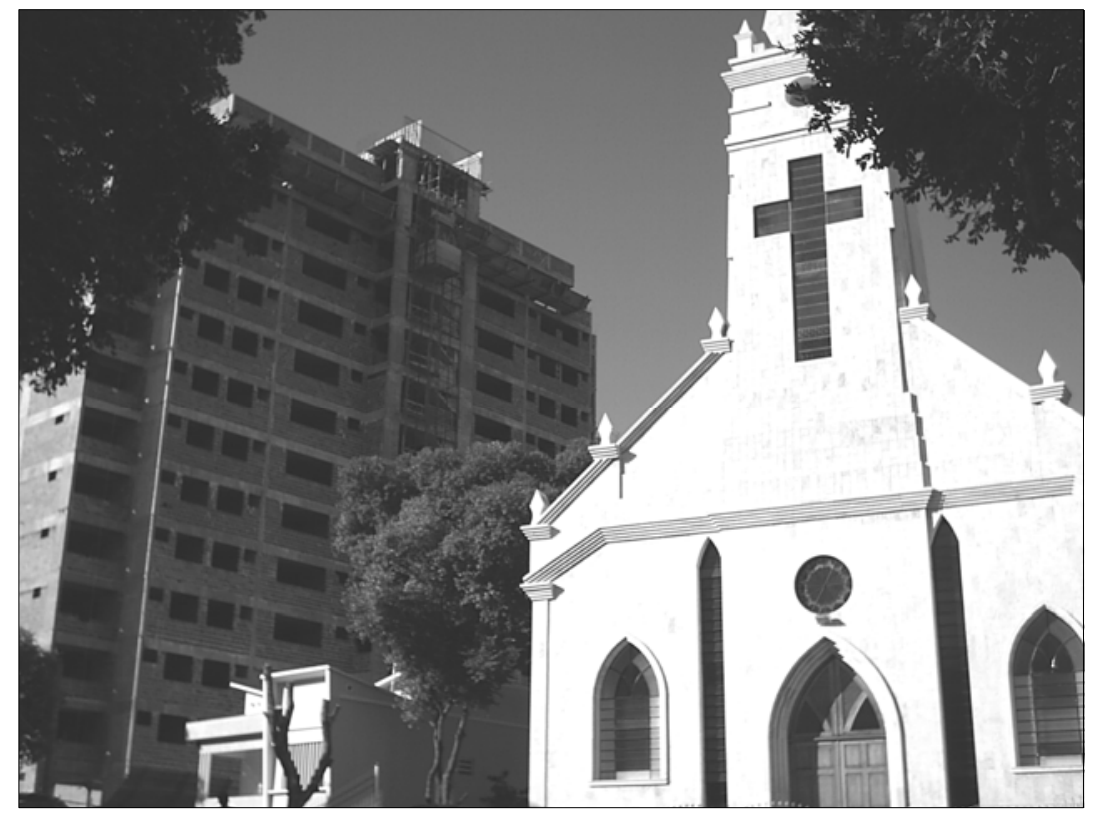

Figura 5: Vista da Catedral de Santo Antônio, com a nova construção ao fundo. Fonte: Acervo da Autora, 2007.

Neste ponto, é necessário esclarecer que estou falando do patrimônio como "projeto da sociedade" e não só como política, seja municipal ou estadual. Várias ações, ou nãoações, não devem ser creditadas apenas ao Conselho, mas devem ser entendidas como solicitações e demandas da cidade, que muitas vezes não se efetivaram, como mostra o exemplo citado. O empreendimento foi um sucesso, do ponto de vista do mercado imobiliário, sendo suas unidades rapidamente comercializadas, o que demonstra que, salvo raras exceções, foi bem aceito localmente. Poderia me atrever a dizer que o sonho de progresso, associado à modernidade, representado, no caso, pelo 
prédio de luxo em local nobre, é mais forte que o sentimento de perda, em relação ajá-antiga posição de destaque da Catedral (Figura 6).

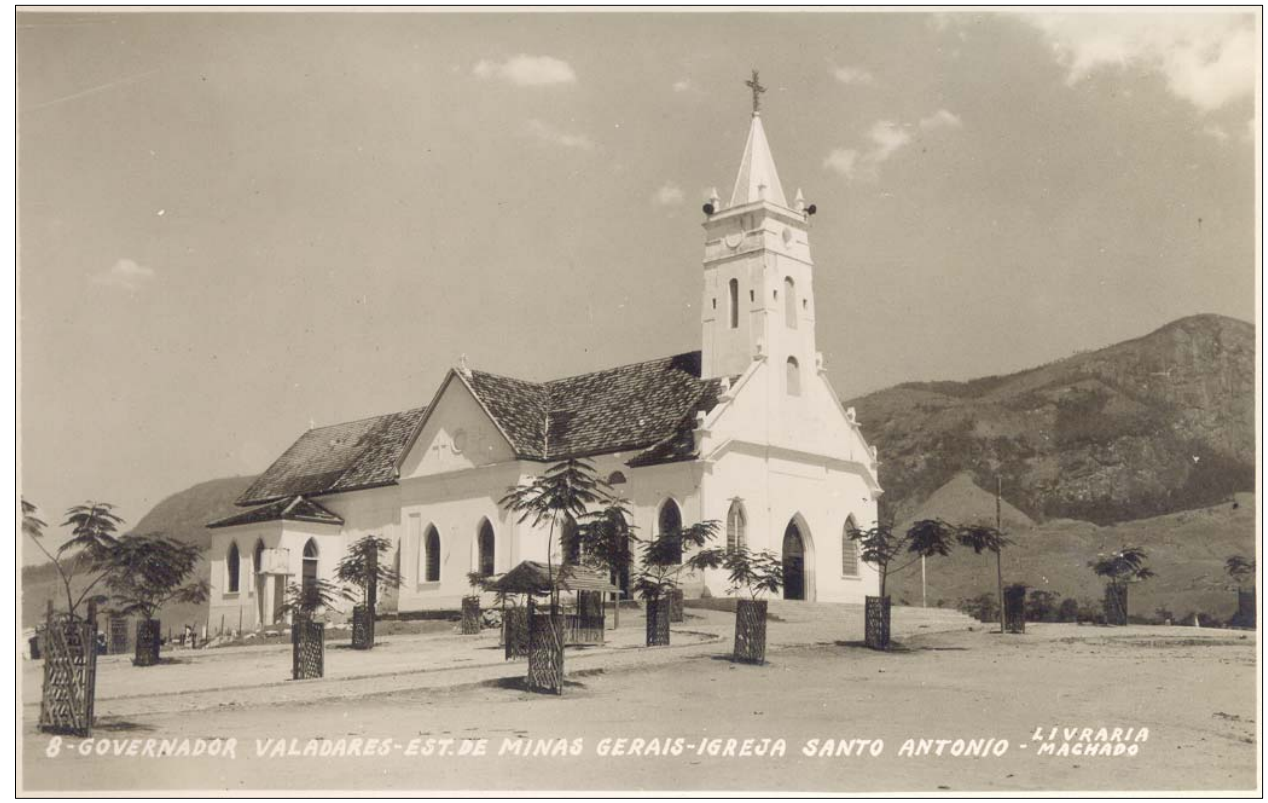

Figura 6: Vista da Catedral de Santo Antônio, década de 1950. Fonte: Arquivos CEDAC/UNIVALE.

\section{Considerações finais}

Novos valores marcam, como visto, o interesse pela implementação do projeto preservacionista em Governador Valadares. Já se faz presente a institucionalização da participação popular, através da gestão democrática das cidades, colocada tanto pela Constituição Federal de 1988, pelo Estatuto da Cidade, como pela Lei Robin Hood, no contexto mineiro. Nesse sentido, as vias legais para a participação estão abertas. Governador Valadares está trilhando um caminho nessa direção, com a criação da política municipal do patrimônio e a implementação do conselho. Contudo, isso não parece ser suficiente.

Os idealizadores da preservação do patrimônio cultural em Governador Valadares não conseguiram sensibilizar a sociedade, que, ao que parece, não aderiu ao projeto de preservação do patrimônio como um todo, nem, tampouco, compreendem o urbano como de todos. As idéias de Gonçalves (1996) são explicativas. Para esse autor as narrativas sobre patrimônio cultural implicam o impulso de preservar os diversos bens 
culturais que estariam sob ameaça de destruição. Porém, esses bens têm que estar sob o risco de perda iminente para que possam ser desejados, e logo, preservados. Ou seja, a perda não é algo exterior, mas parte das próprias estratégias discursivas de apropriação do patrimônio cultural. Contudo, segundo o próprio autor, como essa perda não é um fato histórico, cabe perguntar: para quem o patrimônio estaria sob o risco de se perder?

As respostas a essa questão não são iguais. Alguns segmentos da sociedade brasileira não entendem, por certo, essa perda como um problema; outros, acreditam que isso constitui um problema, mas por razões diversas às colocadas pelo discurso oficial da instituição responsável pelo patrimônio. Uma outra parcela pode concordar com as colocações dessa instituição. Um exemplo ilustrativo é a relação da população católica de uma paróquia com a igreja - edificação - que freqüentam. Essas pessoas, em sua maioria, não tomarão como uma perda a alteração ou substituição de um detalhe ou mesmo de todo o conjunto arquitetônico da igreja freqüentada por motivos religiosos (GONÇALVES, 1996, p. 110). Acredita-se que uma situação análoga a essa acontece em Governador Valadares: os moradores não consideram que o seu patrimônio esteja se perdendo.

Os valadarenses ao invés de se envolverem com a preservação e recuperação dos seus "lugares de memória", não os percebem como tais. Diferente disso, ainda sonham com o futuro, trazido pelas mãos do progresso. Esse sonho de progresso que embalou os primeiros desbravadores e pioneiros, através dos símbolos da modernidade, tão bem representada pela ferrovia, sobrevive no imaginário popular. Talvez seja a hora de perceber que o futuro se fez passado, e seu símbolos estão se tornando ruínas...

\section{Notas}

(1) Governador Valadares é um município do estado de Minas Gerais. Em 2006, sua população estimada era de 250.612 habitantes, segundo dados do IBGE. É um pólo econômico do Vale do Rio Doce, exercendo significativa influência sobre o leste e nordeste de Minas Gerais e municípios do estado do Espírito Santo. Situa-se à margem 
esquerda do Rio Doce, a 324 km de Belo Horizonte. A cidade é servida pela ferrovia Vitória-Minas, da CVRD, e pela rodovia Rio-Bahia (BR-116). Está também ligada à capital do estado pela BR-381.

(2) Em 31 de dezembro de 1937, foi criado o município de Figueira, desmembrado de Peçanha, por ato do governador Benedito Valadares. O Decreto-lei $n^{\circ} 148$, de 17 de dezembro de 1938, mudou seu nome para Governador Valadares.

(3) Edifício onde antes funcionava a Companhia Açucareira Rio Doce (CARDO), que se tornou uma importante referência da história econômica local, foi um empreendimento mantido pela Companhia Belgo Mineira para a produção de açúcar e álcool. Efetivada em 1948, chegou a produzir 600 sacas de açúcar e 10 mil litros de álcool por dia, sendo desativada em 1978. Atualmente o imóvel pertence ao município. Está em situação precária de conservação, mas sensibiliza a população, sendo vários os projetos de readequação da edificação. Atualmente, é utilizada na realização de eventos, sendo o mais famoso a Festa à Fantasia, que reúne milhares de pessoas, dividindo opiniões sobre a adequação desse tipo de uso ao estado de conservação da construção.

(4) O crescimento vertiginoso da cidade, com grande expansão das construções, não é uma preocupação atual, pela estagnação em que se encontra a economia local, mas pode configurar-se como tal, assim que o quadro econômico mude.

\section{Referências bibliográficas}

CÂMARA MUNICIPAL DE GOVERNADOR VALADARES. Lei complementar $n^{\circ}$ 55, de 27/05/2004 (Processo $n^{\circ}$ 1109/2003). Institui o Código Ambiental do Município de Governador Valadares e dá outras providências.

DATAGERAIS. Índice Mineiro de Responsabilidade Social. Disponível em: www.datagerais.mg.gov.br. Acesso em: 18 fev. 2007

FARIA, H.; MOREIRA, A. Cultura e governança: um olhar transversal para o futuro do município. In: Mobilização cidadã e inovações democráticas nas cidades. Edição especial para o Fórum social Mundial. São Paulo: Instituto Polis, 2005.

FUNDAÇÃO JOÃO PINHEIRO. Repasse de ICMS - critério patrimônio cultural. Disponível em: www.fjp.gov.br/produtos/cees/robin hood. Acesso em: 18 fev. 2007.

GONÇALVES, J. R. S. A retórica da perda: os discursos do patrimônio cultural no Brasil. Rio de Janeiro: Editora UFRJ/MinC-IPHAN, 1996.

HABERMAS, Jurgen. O "espaço público" 30 anos depois. Tradução Vera Ligia Westin e Lúcia Lamounier. Caderno de Filosofia e Ciências Humanas: revista do Centro Universitário Newton Paiva, [s.I.], v. 7, n. 12, 12 abr. 1999. 
IEPHA/MG. Bens tombados no estado de Minas Gerais. Disponível em: www.iepha.mg.gov.br. Acesso em: 15 fev. 2007.

IEPHA/MG. Política de Patrimônio. Disponível em: www.iepha.mg.gov.br. Acesso em: 18 fev. 2007.

PEREIRA, M. L. D. Negociações e parcerias: o desafio da gestão urbana democrático-participativa. Teoria e sociedade, [s.I.], n. 6 , p. 212-244, out. 2000.

PREFEITURA MUNICIPAL DE GOVERNADOR VALADARES. Lei Complementar $n^{\circ}$ 004, de 1993. Dispõe sobre o uso e ocupação do solo no município de Governador Valadares.

PREFEITURA MUNICIPAL DE GOVERNADOR VALADARES. Regimento do Conselho Deliberativo do Patrimônio Cultural de Governador Valadares, MG. Governador Valadares, 2002.

PREFEITURA MUNICIPAL DE GOVERNADOR VALADARES. Decreto Municipal, $n^{\circ}$ 8413, de 26/12/2005.

SANTOS, M. O retorno do território. In: SANTOS, M.; SOUZA, M. A.; SILVEIRA, M. L. (Orgs). Território, globalização e fragmentação. São Paulo: Hucitec, 1994.

TEIXEIRA, Elenaldo C. Conselhos de políticas públicas: efetivamente uma nova institucionalidade participativa?. In: CARVALHO, Maria do Carmo A. A.; TEIXEIRA, Ana Claudia C. Conselhos gestores de políticas públicas. São Paulo: Instituto Polis, 2000. p. 97-120. (Publicações Polis, 37).

TRANSPARÊNCIA GV - Primeiro destombamento de patrimônio histórico no Brasil. Disponível em: www.transparenciagv.com. Acesso em: 24 mar. 2006.

VENDA do Seu Margarido desmorona. Hoje em Dia, [s.I.], 6 ago. 2006.

${ }^{*}$ Arquiteta urbanista, Mestre em Arquitetura e Urbanismo, Professora Adjunta da Universidade Vale do Rio Doce.

Trabalho decorrente da pesquisa "Possibilidades da participação na política urbana de Governador Valadares", realizada no âmbito do Programa Gestão do Território/NEHT/UNIVALE. 